\title{
Adolescentes em conflito com a lei nas pesquisas em educação: um olhar a partir de dissertações e teses
}

\author{
Adolescents in conflict with the law in educational research: a look \\ from dissertations and theses
}

\section{Adolescentes en conflicto con la ley en la investigación educativa: una mirada desde las disertaciones $y$ tesis}

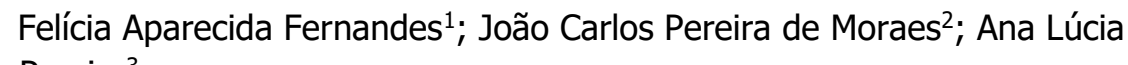
Pereira $^{3}$

\section{RESUMO}

Este artigo objetiva analisar os enfoques de pesquisa em educação, tanto em dissertações quanto em teses, que possuem como sujeitos adolescentes em conflito com a lei. Como procedimento metodológico, foi realizado uma revisão sistemática da literatura nas bases de dados da Coordenação de Aperfeiçoamento de Pessoal de Nível Superior e na Biblioteca Digital de Teses e Dissertações. Neste, realizou-se duas buscas: a primeira utilizando como termos "adolescente" AND "conflito com a lei" AND "ensino"; na segunda, os termos elencados foram "adolescente" AND "infrator" AND "ensino". Para organização e análise dos dados utilizou-se a análise de conteúdo de Bardin, onde quatro categorias foram identificadas: 1) Aspectos sociais, psicológicos e culturais da vida de adolescentes em conflito com a lei; 2) Perspectivas de ensino para adolescentes em conflito com a lei; 3) Relação escola/educação escolar com adolescentes em conflito com a lei; e, 4) Educação não escolar e adolescentes em conflito com a lei. Com a análise, concluímos a necessidade de encontrar as falhas no sistema socioeducativo brasileiro, bem como a busca por novas metodologias e ações para o trabalho com esses adolescentes.

Palavras-chave: Socioeducação; Adolescente em conflito com a lei; Revisão de literatura.

\begin{abstract}
This article aims to analyze the research approaches in education, both in dissertations and theses, that have adolescents in conflict with the law as subjects. As a methodological procedure, a systematic literature review was carried out in the databases of the Coordination for the Improvement of Higher Education Personnel and in the Digital Library of Theses and Dissertations. In this one, two searches were made: the first using as terms "adolescent" AND "conflict with the law" AND "teaching"; in the second, the terms listed were "adolescent" AND "offender" AND "teaching". After analysis of titles, abstracts and duplicity, the number of dissertations and theses was twenty-seven. After analysis of titles, abstracts and duplicity, the number of dissertations and theses was twenty-seven. For the organisation and analysis of the data, content analysis was used from which four categories were identified: 1) Social, psychological and cultural aspects of the life of adolescents in conflict with the law; 2) Educational prospects for adolescents in conflict with the law; 3) School/school relationship with adolescents in conflict with the law; and 4) Non-school education and adolescents in conflict with the law. As a result, it is pointed out that there are some gaps in research on the need to create strategies and theoretical-
\end{abstract}

\footnotetext{
${ }^{1}$ Mestranda em Ensino de Ciências e Educação Matemática da Universidade Estadual de Ponta Grossa (UEPG), Ponta Grossa/PR - Brasil.

${ }^{2}$ Doutor em Educação e docente da Fundação Universidade Federal do Pampa (UNIPAMPA), Jaguarão/RS Brasil.

${ }^{3}$ Doutora em Ensino de Ciências e Educação Matemática e docente dos Programas de Pós-Graduação em Educação e em Ensino de Ciências e Educação Matemática da Universidade Estadual de Ponta Grossa (UEPG), Ponta Grossa/PR - Brasil.
} 
methodological perspectives that allow for a humanized, problematized and more open listening to this group of adolescents.

Keywords: Socio-education; Adolescent in conflict with the law; Literature review.

\section{RESUMEN}

Este artículo pretende analizar los enfoques de investigación en educación, tanto en disertaciones como en tesis, que tienen como sujetos a adolescentes en conflicto con la ley. Para ello se utilizó como base de datos la Biblioteca Digital Brasileña de Tesis y Disertaciones de CAPES (BDTD). En esta, se hicieron dos búsquedas: la primera utilizando como términos "adolescente" $Y$ "conflicto con la ley" $Y$ "enseñanza"; en la segunda, los términos listados fueron "adolescente" $Y$ "delincuente" $Y$ "enseñanza". Después de analizar el título, los resúmenes y la duplicidad, el número de disertaciones y tesis fue de veintisiete. Después de analizar los títulos, resúmenes y duplicidades, el número de disertaciones y tesis fue de veintisiete. Para organizar y analizar los datos se utilizó un análisis de contenido a partir del cual se identificaron cuatro categorías: 1) Aspectos sociales, psicológicos y culturales de la vida de los adolescentes en conflicto con la ley; 2) Perspectivas educativas para los adolescentes en conflicto con la ley; 3) Relación de la educación escolar/escuela con los adolescentes en conflicto con la ley; y, 4) Educación no escolar y adolescentes en conflicto con la ley. Como resultados, se señala que existen algunas lagunas en la investigación sobre la necesidad de crear estrategias y perspectivas teórico-metodológicas que permitan una escucha humanizada, problematizada y más abierta de este grupo de adolescentes.

Palabras clave: Socio-educación; Adolescente en conflicto con la ley; Revisión de la literatura.

\section{INTRODUÇÃO}

O processo educativo em contextos de socioeducação e a escolarização de adolescentes em conflito com a lei possuem elementos complexos, tais como realidade local, interesses dos educandos, históricos de evasão escolar, etc. Quanto às características deste grupo, segundo dados divulgados pelo Departamento de Atendimento Socioeducativo - DEASE (2017), a maioria dos adolescentes ingressa no Centro Socioeducacional entre 16 e 17 anos de idade e apresenta grande defasagem escolar, sendo que a média não ultrapassa o $6^{\circ}$ ano do Ensino Fundamental.

Nesse sentido, consideramos a necessidade de um olhar crítico para as abordagens em pesquisas educacionais adotadas junto a tal grupo, visando potencializar as implicações sociais e de ensino destes estudos. Perante o contexto citado, este artigo objetiva analisar os enfoques de pesquisa em educação, tanto em dissertações quanto em teses, que possuem como sujeitos adolescentes em conflito com a lei. Para tanto, utilizou-se como banco de dados a Biblioteca Digital Brasileira de Teses e Dissertações da CAPES (BDTD).

Como pressuposto de organização deste estudo, estruturamo-lo da seguinte forma: (1) breve debate referente à escolarização e socioeducação; (2) Percurso metodológico, com a estrutura da revisão; (3) Resultados, dividido em quatro categorias suscitada a partir do levantamento; (4) Discussões dos resultados anteriores; e, por fim, (5) Considerações finais. 


\section{ESCOLARIZAÇÃO E SOCIALIZAÇÃO}

A partir de 1990, com o Estatuto da Criança e do Adolescente (Ecriad) e sua política de proteção integral para a organização das instituições de internação no Brasil, novos modos de pensar a adolescência e a sua escolarização em unidades socioeducativas são potencializados. Nesse sentido, a seguir apontamos alguns aspectos destas questões.

\subsection{0 ser adolescente}

A adolescência pode ser compreendida como um fenômeno no desenvolvimento humano, no qual ocorre a transição da infância para a fase adulta, que é marcada por vários conflitos internos e externos em relação ao mundo. Selosse (1997) citada por Gomes e Conceição (2014, p. 48):

Considera a adolescência como a transição entre a dependência infantil e a autonomia adulta, marcada por transações afetivas relacionais, sociocognitivas, sexuais, identitárias e normativas, de lutos e desilusões, de prazer e gozo, que não ocorrem sem angústia ou conflitos.

Assim, esta transição não engloba somente às transformações físicas e biológicas do ser humano, mas também os conflitos e angústias da transformação e adaptação psicológica, familiar e social do indivíduo. O processo de tornar-se um adulto é marcado por experiências e experimentações feitas pelo adolescente para que possa se apropriar de si mesmo e de seu corpo. Tais experimentações podem ou não se tornar permanentes.

Neste contexto, a rebeldia e o enfrentamento das regras podem se tornar uma ferramenta de experimentações juntamente com a necessidade de pertencimento inerente neste período de transição. A conduta transgressora do adolescente pode ser considerada um momento de ampliação dos aspectos sociais e individuais, uma forma de criar uma nova rede de relacionamentos e a oportunidade de desempenhar novos papéis sociais e uma forma de ressignificar os papéis sociais já construídos (GOMES; CONCEIÇÃO, 2014).

Takeuti (2002, p.25) compreende os adolescentes como a "porção social mais destituída de valores referenciais e privada de âncoras identificatórias estáveis", ou seja, as relações sociais imediatas vivenciados por este grupo tem grande influência em suas ações e na construção de sua personalidade. Outro fator que influencia nessa construção é a situação econômica dos adolescentes, como nos mostra Veloso (2016, p. 4):

Sobre os jovens das classes economicamente menos favorecidas, estes fatores podem ter consequências mais graves: se por um lado exige-se do jovem maior perseverança e vigor para o acesso aos bens de consumo e uma colocação no mercado de trabalho, por outro lado pode-se gerar um sentimento de frustração e impotência, em especial, quando o foco está na individualidade, na meritocracia, no sentimento do "ter" em detrimento do "ser".

Neste caso, a situação econômica do adolescente pode ser um agravante para o ato infracional. Nesta perspectiva, o ato infracional pode ser entendido como uma forma de lidar com conflitos ou, ainda, uma forma de se posicionar na sociedade, uma última tentativa de mostrar as falhas nos sistemas familiar e social. 


\subsection{Escolarização em unidades socioeducativas}

No contexto de unidades socioeducativas, as propostas educacionais adquirem características que tangem tanto a escolarização quanto à formação social de seus educandos. Frente a isso, as questões educacionais devem primar por possibilidades de transformação da realidade dos adolescentes e superação de atos infracionais.

Como previsto no Ecriad (BRASIL, 1990), a função da escola e da sociedade consiste em oportunizar uma formação integral a todos os sujeitos, de forma que o mesmo compreenda o seu contexto, mediante os princípios éticos e pressupostos normativos em que nele são delineados. Não podendo esquecer, ainda, que, além de deveres, esses adolescentes são sujeitos de direitos que devem ser assegurados.

Para atender as especificidades e as singularidades do grupo, segundo o DEASE (2017, p. 33), nos Centros de Socioeducação é ofertado a Educação Básica, na modalidade de Educação de Jovens e Adultos (EJA) e cursos profissionalizantes, além de oportunizar a realização de exames nacionais e estaduais de progressão educacional, tais como os Exames Estaduais de Educação de Jovens e Adultos e o Exame Nacional do Ensino Médio para pessoas privadas de liberdade (ENEM/PPL). Já para os adolescentes em medidas de semiliberdade, a matrícula é realizada em instituições da rede estadual de ensino, próximas às unidades de atendimento.

Além das modalidades da Educação Básica e dos Cursos de Qualificação Profissional, são ofertados Projetos de Cultura, Esporte e Lazer, que contam com oficinas de: musicalização; dança; arte circense; capoeira; cinema; artes cênicas; expressão corporal e teatro. Essas práticas consolidam-se a partir do objetivo de uma formação integral aos educandos e a promoção de outros modos de vivenciar a realidade.

\section{PERCURSO METODOLÓGICO}

Mediante o objetivo deste estudo, inicialmente foram realizadas duas buscas de trabalhos na Biblioteca Digital Brasileira de Teses e Dissertações. A primeira delas utilizando como termos de busca "adolescente" AND "conflito com a lei" AND "ensino", em que foram encontrados cinquenta e um (51) trabalhos. Na segunda, utilizando os termos "adolescente" AND "infrator" AND "ensino", foram levantados vinte e um trabalhos (21). Deste modo, encontramos o total de setenta e dois (72) trabalhos, realizados durante o período de 2004 à 2019.

Em análise inicial dos títulos das produções, retiraram-se os trabalhos repetidos, o que sobrou cinquenta e dois (52) estudos. Após a análise dos títulos, realizou-se a leitura dos resumos dos trabalhos, a fim de selecionar somente as produções em que a pesquisa foi realizada diretamente com os adolescentes em conflito com a lei. Com esta seleção, atingimos vinte e sete (27) de mestrado ou doutorado.

Com as filtragens, bem como a leitura dos resumos, utilizamos, para identificar as principais características das pesquisas analisadas, a análise de conteúdo de Bardin que consiste em:

"um conjunto de técnicas de análise das comunicações visando a obter, por procedimentos sistemáticos e objetivos de descrição do conteúdo das mensagens, indicadores (quantitativos ou não) que permitam a inferência de conhecimentos 
relativos às condições de produção/recepção (variáveis inferidas) destas mensagens (Bardin, 2011, p. 47).

Dessa etapa, foi possível identificarmos quatro categorias: 1) Aspectos sociais, psicológicos e culturais da vida de adolescentes em conflito com a lei; 2) Perspectivas de ensino para adolescentes em conflito com a lei; 3) Relação escola/educação escolar com adolescentes em conflito com a lei; e, 4) Educação não escolar e adolescentes em conflito com a lei.

\section{RESULTADOS}

\subsection{Categoria I - Aspectos sociais, psicológicos e culturais da vida de adolescentes em conflito com a lei}

Esta categoria reuniu oito trabalhos, sendo eles duas teses e seis dissertações, os quais têm como enfoque a análise dos aspectos sociais, psicológicos e culturais da vida dos adolescentes. Os estudos abordam os fatores relacionados à trajetória de vida dos adolescentes e suas implicações no processo de ensino e aprendizagem.

Quadro 1: Grupo 1 - Aspectos sociais, psicológicos e culturais da vida de adolescentes em conflito com a lei

\begin{tabular}{|c|c|c|c|c|}
\hline AUTOR & TÍTULO & ANO & PPG & IES \\
\hline MIRANDA & $\begin{array}{l}\text { Adolescente em conflito com a lei e a } \\
\text { lei em conflito com o adolescente: } \\
\text { processo de criminalização da } \\
\text { adolescência pobre }\end{array}$ & 2016 & $\begin{array}{l}\text { Psicologia } \\
\text { Institucional }\end{array}$ & UFES \\
\hline PADOVANI & $\begin{array}{l}\text { Resolução de problemas sociais com } \\
\text { adolescentes em conflito com a lei: } \\
\text { estratégias de mensuração e } \\
\text { intervenção Resolução de problemas } \\
\text { sociais com adolescentes em conflito } \\
\text { com a lei: estratégias de mensuração } \\
\text { e intervenção }\end{array}$ & 2008 & $\begin{array}{l}\text { Educação } \\
\text { Especial }\end{array}$ & UFSCAR \\
\hline MACEDO & $\begin{array}{c}\text { Características psicossociais e de } \\
\text { personalidade de adolescentes } \\
\text { infratores em cumprimento de medida } \\
\text { socioeducativa }\end{array}$ & 2016 & $\begin{array}{l}\text { Psicologia da } \\
\text { Saúde }\end{array}$ & UNESP \\
\hline TAYLOR & $\begin{array}{l}\text { As representações do psicólogo na } \\
\text { socioeducação: o saber ingênuo de } \\
\text { adolescentes em internação provisória } \\
\text { e em cumprimento de medidas } \\
\text { socioeducativas no DEGASE }\end{array}$ & 2015 & Psicologia & UFRRJ \\
\hline SANTOS & $\begin{array}{l}\text { As adolescentes em cumprimento de } \\
\text { medida socioeducativa: um diálogo } \\
\text { sobre as questões de gênero, } \\
\text { escolarização, sociedade de consumo } \\
\text { e ato infracional }\end{array}$ & 2016 & Educação & UNB \\
\hline
\end{tabular}




\begin{tabular}{|c|c|c|c|c|}
\hline MASSARO & $\begin{array}{c}\text { Entre o formal e o real: } \\
\text { representações acerca do modelo } \\
\text { disciplinar da fundação casa de } \\
\text { Araraquara }\end{array}$ & 2008 & Educação & UNESP \\
\hline PACHECO & $\begin{array}{c}\text { A construção do comportamento anti- } \\
\text { social em adolescentes autores de } \\
\text { atos infracionais: uma análise a partir } \\
\text { das práticas educativas e dos estilos } \\
\text { parentais }\end{array}$ & 2004 & $\begin{array}{c}\text { Psicologia do } \\
\text { Desenvolviment } \\
\text { GOMES }\end{array}$ & $\begin{array}{c}\text { Adolescentes autores de atos } \\
\text { infracionais e histórias de vida: } \\
\text { construindo histórias em intervenção } \\
\text { grupal no contexto da medida } \\
\text { socioeducativa de liberdade assistida }\end{array}$ \\
\hline
\end{tabular}

Fonte: Elaboração dos autores (2020).

Na dissertação de Miranda (2016), intitulado como "Adolescente em conflito com a lei e a lei em conflito com o adolescente: processo de criminalização da adolescência pobre", a autora busca problematizar a criminalização da adolescência pobre, analisando os princípios norteadores da socioeducação no Brasil, bem como dados estatísticos, nacionais e regionais, sobre o tema. O lócus da pesquisa foi uma Escola Municipal de Ensino Fundamental de Educação de Jovens e Adultos, na qual estudam vários adolescentes em cumprimento de medida socioeducativa. A metodologia utilizada foi a etnografia e o diário de campo como instrumento de pesquisa.

Com a análise, a autora evidencia o trabalho da Política Neoliberal em prol da criminalização da pobreza, bem como da redução da maioridade penal. Refletindo sobre a necessidade de as instituições, que atendem os sujeitos estudados, passarem por constantes reflexões e transformações. Para que, neste contexto, não se tornem reprodutoras da ideologia de criminalização da infância e adolescência, mas sim garantir o acesso aos direitos fundamentais dos indivíduos.

Padovani (2008), por sua vez em sua tese, produziu dois estudos, sendo que o primeiro teve como objetivo a emissão de respostas socialmente competentes favorecedoras ao bem-estar psicossocial de adolescente, por meio de uma intervenção com esse grupo na Fundação CASA. Para a coleta de dados, utilizou como instrumentos o roteiro de entrevista individual, Inventário de Depressão Beck (BDI), Inventário de Ansiedade Beck (BAI), Inventário de Desesperança de Beck (BHS), Inventário de Resolução de Problemas Sociais Revisado: Forma Abreviada (SPSI-R:S) e Teste de Desempenho Escolar (TDE). Já o segundo estudo teve como objetivo validar, para uso, o Inventário de Resolução de Problemas Sociais-Revisado: Forma Abreviada (SPSR:S), bem como investigar a evidência de validade de conteúdo e critério. Este estudo foi realizado com adolescentes em medida socioeducativa e estudantes regulares de uma escola estadual.

Os resultados obtidos no Estudo 1 indicam histórico de fracasso escolar; histórico de maus-tratos infantis, consumo de bebidas alcoólicas e drogas ilícitas, e envolvimento em lutas corporais, além de ser possível verificar um índice expressivo de abandono da intervenção, sendo que apenas dois participantes estiveram presentes em todas as sessões. O Estudo 2 teve como resultados $95 \%$ de validade do instrumento utilizado, sendo que o mesmo foi capaz de discriminar populações de infratores e não infratores com base na pontuação dos adolescentes no teste. 
Também no âmbito da psicologia, a dissertação "Características psicossociais e de personalidade de adolescentes infratores em cumprimento de medida socioeducativa" de Macedo (2016) buscou levantar e descrever indicadores socioculturais de uma amostra de adolescentes em cumprimento de medida socioeducativa, bem como descrever características psicológicas e de personalidade dos adolescentes infratores por meio de uma abordagem psicanalítica pós-freudiana. A autora utilizou-se de entrevistas semidirigidas para selecionar os adolescentes que posteriormente foram submetidos a um instrumento projetivo para investigação de aspectos da personalidade: o "Desenho da Figura Humana" de Machower.

Macedo (2016) traz como resultados padrões comuns de comportamento no período da adolescência que estão diretamente ligados a fatores sociais, culturais e familiares. O estudo destacou a problemática do adolescente em conflito com a lei, associada às questões sociais, de saúde mental, além do desenvolvimento psíquico, sinalizando a necessidade de ações psicoprofiláticas voltadas para população infantil, jovem, agrupamentos familiares e para a comunidade que representa seu entorno.

Taylor (2015), com a dissertação "As representações do psicólogo na socioeducação: o saber ingênuo de adolescentes em internação provisória e em cumprimento de medidas socioeducativas no DEGASE", buscou identificar às representações que os adolescentes em cumprimento de medidas socioeducativas têm do Psicólogo que atua no Departamento Geral de Ações Socioeducativas (DEGASE) do estado do Rio de Janeiro, bem como refletir sobre o papel do psicólogo no trabalho socioeducativo. Neste contexto a autora utiliza a metodologia de análise discursiva e como instrumentos o diário de campo, bem como uma palavra indutora para a análise do discurso dos adolescentes.

Com o estudo, a autora aponta que o Psicólogo, que atua na área de socioeducação, tem a representação de um profissional que ajuda, atende, conversa, que alivia suas angústias durante o período de permanência no DEGASE e que também é reconhecido por seu nome pelos adolescentes, constatando-se como um profissional benéfico e de grande importância para os adolescentes e seus familiares.

A dissertação de Santos (2016), intitulado "As adolescentes em cumprimento de medida socioeducativa: um diálogo sobre as questões de gênero, escolarização, sociedade de consumo e ato infracional", buscou analisar, por meio dos pressupostos psicanalíticos, a constituição da história de vida, focalizando o processo de escolarização e as questões de gênero das adolescentes em cumprimento de uma das medidas socioeducativas no Distrito Federal. A autora utilizou-se de escutas clínicas das adolescentes entrevistadas, bem como de grupos de reflexão para alcançar os objetivos da pesquisa.

A pesquisa traz como resultados que o desejo de futuro das meninas apareceu vinculado ao acesso aos bens de consumo. Aspecto este preocupante por poder reconduzi-las ao crime, sendo que as adolescentes diante da educação ofertada nas escolas públicas se excluem desse espaço ao serem seduzidas para o ingresso na "escola do crime". Exclusão esta que é facilitada pelo ideal estético, sendo possível perceber um estreito diálogo entre questões de gênero, escolarização, adolescência e sociedade de consumo para a compreensão do engajamento das meninas nas condutas infracionais.

"Entre o formal e o real: representações acerca do modelo disciplinar da fundação casa de Araraquara", dissertação de Massaro (2008), traz como objetivo analisar e discutir o modelo disciplinar praticado na Unidade de Internação da Fundação Centro de Atendimento Socioeducativo 
ao Adolescente - Fundação CASA - antiga Fundação Estadual do Bem-Estar do Menor - FEBEM - do município de Araraquara. A autora buscou fazer análises das representações sociais, por meio de entrevistas compreensivas com adolescentes, professores e funcionários da instituição.

O estudo conclui que é possível perceber diversas contradições entre o discurso formal e as práticas executadas no que se refere à disciplina, controle e punição no interior da Unidade, ancoradas no senso comum e na ideologia dominante de que tais procedimentos possuem um caráter pedagógico no sentido de adaptar os adolescentes atendidos às normas sociais vigentes.

Pacheco (2004) em sua tese "A construção do comportamento antissocial em adolescentes autores de atos infracionais: uma análise a partir das práticas educativas e dos estilos parentais", tem como objetivo comparar as variáveis familiares relacionadas ao desenvolvimento de adolescentes infratores e não infratores, bem como analisar as variáveis que precedem a conduta infratora. A pesquisa foi realizada em vários locais, sendo uma unidade socioeducativa do estado do Rio Grande do Sul e escolas públicas da cidade de Porto Alegre. Os instrumentos utilizados pela autora foram a entrevista estruturada, a Escala de Estilos Parentais e a análise dos prontuários dos adolescentes em medida socioeducativa.

A pesquisa aponta que as variáveis independentes, como o comportamento antissocial na família, o número de irmão, uso de drogas pelo adolescente, conflitos na família, dentre outros, contribuíram para explicar $53 \%$ da variância do comportamento infrator.

Na dissertação "Adolescentes autores de atos infracionais e histórias de vida: construindo histórias em intervenção grupal no contexto da medida socioeducativa de liberdade assistida" de Gomes (2012), a autora tem como objetivo compreender a trajetória infracional de adolescentes vinculados à medida socioeducativa de Liberdade Assistida (LA), por meio do método de história de vida, tendo como intuito o engajamento dos adolescentes no trabalho de narradores e coprodutores. $\mathrm{O}$ lócus da pesquisa não foi uma instituição de internação, pois os adolescentes cumprem medidas de liberdade assistida, por este motivo foram realizados encontros grupais para a coleta de dados, utilizando-se dos métodos socioeconômico e da história de vida.

Os resultados da pesquisa apontam que o método de história de vida em modalidade grupal foi capaz de fornecer informações relevantes para a compreensão da trajetória infracional dos adolescentes, constituindo-se em poderosa ferramenta de pesquisa-intervenção junto a essa clientela, bem como, é possível perceber o potencial socioeducativo da medida de liberdade assistida favorecendo a reconciliação entre o passado, presente e futuro, por meio de ações que visem o empossamento dos espaços perdidos pelos adolescentes.

\subsection{Categoria II - Perspectivas de ensino para adolescentes em conflito com a lei}

Nesta categoria foram elencadas sete produções, sendo duas teses e cinco dissertações, as quais têm como enfoque as perspectivas de ensino para adolescentes em conflito com a lei. Os estudos desse grupo refletem sobre novas metodologias e formas de ensino que favoreçam o processo de ensino e aprendizagem de adolescentes em conflito com a lei, bem como a necessidade de mudança nas formas de ensino estabelecidas nas instituições de socioeducação. 
Quadro 2: Grupo 2 - Perspectivas de ensino para adolescentes em conflito com a lei.

\begin{tabular}{|c|c|c|c|c|}
\hline AUTOR & TÍTULO & ANO & PPG & IES \\
\hline GOMES & $\begin{array}{c}\text { Adolescentes em conflito com a lei: o } \\
\text { ensinar e o aprender através das } \\
\text { tecnologias da informação e da } \\
\text { comunicação }\end{array}$ & 2016 & $\begin{array}{l}\text { Informática na } \\
\text { Educação }\end{array}$ & UFRGS \\
\hline PERIPOLLI & $\begin{array}{l}\text { Criatividade: caminho desenhante para } \\
\text { altas habilidades/superdotação do } \\
\text { adolescente em conflito com a lei }\end{array}$ & 2010 & Educação & UFSM \\
\hline COSTA & $\begin{array}{c}\text { A relação entre a escola, o ensino de } \\
\text { línguas e o abandono escolar: um olhar a } \\
\text { partir das crenças e experiências de } \\
\text { adolescentes com quem a lei entra em } \\
\text { conflito }\end{array}$ & 2012 & $\begin{array}{l}\text { Linguagem, } \\
\text { Identidade e } \\
\text { Subjetividade }\end{array}$ & UEPG \\
\hline BASTOS & $\begin{array}{l}\text { "Na escola, o cara tinha que ficá quieto, } \\
\text { olhando pro quadro e escrevendo. Na rua, } \\
\text { eu fazia o que eu queria": fenômenos } \\
\text { representativos de adolescentes em conflito } \\
\text { com a lei sobre as aulas de língua materna, } \\
\text { escolarização e abandono escolar }\end{array}$ & 2019 & $\begin{array}{l}\text { Linguística } \\
\text { Aplicada }\end{array}$ & UNISINOS \\
\hline FERNANDES & $\begin{array}{c}\text { Educação musical de adolescentes em } \\
\text { cumprimento de medida socioeducativa } \\
\text { através do canto coral }\end{array}$ & 2012 & Música & UNICAMP \\
\hline GARCIA & $\begin{array}{l}\text { Tessituras a/r/tográficas: ensino de artes } \\
\text { visuais no centro de referência } \\
\text { especializado de assistência social - São } \\
\text { Gonçalo Do Amarante - RN }\end{array}$ & 2019 & Artes Visuais & UFPE \\
\hline OLIVEIRA & $\begin{array}{c}\text { A delinquência e a (im)possibilidade de se } \\
\text { significar como autor no discurso } \\
\text { matemático }\end{array}$ & 2015 & $\begin{array}{l}\text { Educação Para } \\
\text { A Ciência E A } \\
\text { Matemática }\end{array}$ & UEM \\
\hline
\end{tabular}

Fonte: Elaboração dos autores.

Na produção "Adolescentes em conflito com a lei: o ensinar e o aprender através das tecnologias da informação e da comunicação", tese de Gomes (2016), o autor aborda o uso do Ambiente Virtual de Aprendizagem (AVA). O objetivo do estudo é observar a importância do uso das tecnologias digitais como instrumentos mediadores privilegiados. Refletindo se o uso favorece os processos cognitivos, que levam o sujeito a aprender por meio da interação social e da mediação entre as atividades de ensino, bem como viabilizar a criação de um ambiente de aprendizagem colaborativo para os adolescentes em conflito com a lei no Circo Escola em São Luís do Maranhão. Para a coleta de dados, o autor utilizou observações, reuniões com os adolescentes e entrevistas.

Os resultados da pesquisa apontam que o AVA é um dos recursos que pode ser utilizado em contexto educativo, como ferramenta complementar às aulas, pelo seu fácil acesso nos dispositivos móveis e por seu uso tanto pelos estudantes como pelo docente, bem como a necessidade de variar os instrumentos e às formas de ensino, para que este tenha mais qualidade. As principais contribuições para os adolescentes, segundo o autor, perpassam pelo: conhecimento de conteúdos éticos e 
comportamentais de cidadania através das mídias de comunicação e em especial a web; O ensinar e aprender à distância, por meio dos ambientes colaborativos; Construção de variadas produções (chats, fóruns) através da plataforma Moodle; e, por fim, pelos mecanismos de pesquisas online, uma vez que permite ao adolescente o seu envolvimento em atividades colaborativas no AVA.

Já Peripolli (2010), em sua dissertação "Criatividade: caminho desenhante para altas habilidades/superdotação do adolescente em conflito com a lei", aborda a temática da Educação Especial de altas habilidades/ superdotação de adolescentes em conflito com a lei, com objetivo de analisar descritivamente a criatividade de adolescentes institucionalizados e a compreensão desta pelos professores. A pesquisa foi realizada no Centro de Atendimento Socioeducativo da Cidade de Caxias do Sul - RS. Como instrumentos, o autor utilizou entrevistas com professores e adolescentes da instituição, gravações e anotações em diário de campo, bem como a análise narrativa dos discursos dos sujeitos entrevistados.

Com a pesquisa, concluiu-se que o estudo da criatividade resultou na defesa de uma compreensão desta como uma faculdade ontologicamente inerente ao gênero humano, fundamental ao seu constante processo de desenvolvimento, conquanto manifesta-se singularmente, dada a riqueza de diversidade existente entre os seres humanos e em suas relações com a realidade e, no caso dos adolescentes e conflito com a lei, é um indicativo de altas habilidades/superdotação.

Na dissertação de Costa (2012), intitulado "A relação entre a escola, o ensino de línguas e o abandono escolar: um olhar a partir das crenças e experiências de adolescentes com quem a lei entra em conflito", objetivou-se investigar as crenças e as experiências escolares que adolescentes em conflito com a lei trazem de sua vida pré-internação, sendo que o lócus da pesquisa foi o Centro de Socioeducação de Ponta Grossa - PR. Os instrumentos utilizados pelo autor foram observações, entrevistas, anotações em diário de campo e caderno de relatos com questionamentos a serem respondidos pelos adolescentes.

Os resultados da pesquisa apontam que a experiência escolar dos adolescentes não foi algo positivo, pois a escola, para eles, tornou-se um lugar de preconceitos e exclusão, por parte tanto de colegas quanto de professores, tornando-se, a própria escola, uma barreira para a continuidade de sua vida escolar e resultando na evasão do sujeito.

Em "'Na escola, o cara tinha que ficá quieto, olhando pro quadro e escrevendo. Na rua, eu fazia o que eu queria': fenômenos representativos de adolescentes em conflito com a lei sobre as aulas de língua materna, escolarização e abandono escolar", dissertação de Bastos (2019), objetivou analisar os fenômenos representativos expressos por adolescentes que se encontram em cumprimento de medida socioeducativa de internação e estão cursando os anos finais do Ensino Fundamental, abordando a temática de escolarização e abandono escolar. Os instrumentos utilizados para a coleta de dados foram entrevistas em grupo e a técnica de associação de ideias.

Com o estudo, Bastos (2019) concluiu que as falas dos adolescentes demonstram um saber prático do cotidiano em que surgem a rejeição à escola, às ideias de que a vida social não vale a pena e o percurso pelo ato infracional, por uma integração com a criminalidade, meio em que esse jovem se reconhece "incluído". Reconhecem que a frequência à escola no período de internação foi boa, porque obtiveram progressos em seus percursos escolares. Acerca das aulas de língua materna, com base nas suas vivências escolares, os adolescentes representam as aulas como algo que não é significativo a eles. 
Fernandes (2012), em sua tese intitulada "Educação musical de adolescentes em cumprimento de medida socioeducativa através do canto coral", trabalhou a educação musical com adolescentes em cumprimento de medida socioeducativa por meio de aulas de coral em uma unidade da Fundação CASA. O estudo tem como objetivo relatar a experiência e auxiliar a formação do educador musical que pretende trabalhar com esse público.

Durante o trabalho com os adolescentes destacou-se a necessidade de construção de vínculo afetivo com os sujeitos para alcançar alguns objetivos das aulas, bem como a utilização de diversas estratégias de ensino para minimizar problemas com o comportamento dos adolescentes. Conclui-se que os conhecimentos extramusicais relacionados às áreas de conhecimento da sociologia e da psicologia são imprescindíveis para o sucesso do desenvolvimento da educação musical de adolescentes em cumprimento de medida socioeducativa através do canto coral.

Já a dissertação de Garcia (2019) aborda a temática da Educação não-formal de adolescentes em cumprimento de medida de Liberdade Assistida. O estudo tem como objetivo analisar a aplicação da Educação não-formal em artes visuais no âmbito das atividades do Centro de Referência Especializado de Assistência Social, no Município de São Gonçalo do Amarante/RN. Neste contexto, apresenta os resultados da atuação do autor enquanto artista/educador no desenvolvimento das habilidades em artes visuais de nove adolescentes que cumpriam medidas socioeducativas em liberdade assistida na ocasião do desenvolvimento da pesquisa. Os instrumentos utilizados foram questionários, entrevistas, documentos e prontuários dos adolescentes, porém, segundo o autor, a dificuldade de contato com os adolescentes influenciou a coleta de dados.

Os resultados da pesquisa evidenciaram que o ensino não-formal em artes visuais pode proporcionar subsídios para a sensibilização de adolescentes em conflito com a lei, porém faz-se necessário o apoio por meio de políticas públicas de bem estar social para os adolescentes e suas famílias.

Oliveira (2015) em sua dissertação questiona forma de abertura de espaço de autoria dos adolescentes em medida de internação, de um Centro Socioeducativo, na prática matemática, baseando-se em sua trajetória de vida, com o objetivo de analisar os (não) sentidos das matemáticas no discurso do adolescente nas relações produzidas com o social, descritas em suas narrativas de vida e na autoria de Situações Problema. Durante o trabalho foram produzidas, pelos adolescentes, narrativas de vida que auxiliaram na proposta de criação de situações problemas pelos mesmos.

Com a finalidade de compreender nas palavras do adolescente, o seu entendimento sobre a Matemática curricular, ensinada nas escolas como disciplina essencial, concluiu-se que é possível encontrar no discurso do adolescente a possibilidade de (re)visitar o antes que compõe suas condições de produção anteriores à sua internação e realizar um planejamento de um possível depois. Com a aproximação da análise de discurso e a Matemática pelo viés da autoria de situações problema, mostrou-se uma possibilidade diferenciada na atuação pedagógica dentro de uma aula de Matemática que traz mais significado ao aprendizado dos adolescentes.

\subsection{Categoria III - Relação escola/educação escolar com adolescentes em conflito com a lei}

Nesta categoria foram elencadas sete produções, sendo duas teses e cinco dissertações, as quais têm como enfoque a relação escola/educação escolar com adolescentes em conflito com a lei. Os trabalhos desse grupo trazem a reflexão acerca da relação dos adolescentes em conflito com a lei 
com o ambiente escolar, bem como às dificuldades de acesso e permanência desses indivíduos na escola.

Quadro 3: Grupo 3 - Relação escola/educação escolar com adolescentes em conflito com a lei.

\begin{tabular}{|c|c|c|c|c|}
\hline AUTOR & TÍTULO & ANO & PPG & IES \\
\hline SILVA & O adolescente em conflito com a lei na escola & 2019 & Educação & UNINOVE \\
\hline MELO & $\begin{array}{l}\text { A educação profissional na perspectiva do } \\
\text { adolescente em conflito com a lei }\end{array}$ & 2014 & $\begin{array}{l}\text { Educação } \\
\text { Agrícola }\end{array}$ & UFRRJ \\
\hline MONTEIRO & $\begin{array}{l}\text { Adolescentes em conflito com a lei: memórias } \\
\text { e trajetórias de vivências na escola }\end{array}$ & 2010 & Educação & UFPB \\
\hline MARIÁS & $\begin{array}{c}\text { A educação profissionalizante de jovens em } \\
\text { conflito com a lei: interferências do despertar } \\
\text { da puberdade na tarefa de inserção no mundo } \\
\text { do trabalho }\end{array}$ & 2014 & Educação & UFMG \\
\hline PIAZZAROLLO & $\begin{array}{l}\text { Fatores de risco e de proteção presentes na } \\
\text { vida de adolescentes cumprindo liberdade } \\
\text { assistida: permanência e evasão escolar }\end{array}$ & 2015 & Psicologia & UFES \\
\hline SILVA & $\begin{array}{l}\text { Tempo da tranca, tempo da sala: a educação } \\
\text { escolar de adolescentes em cumprimento de } \\
\text { medida socioeducativa em um centro de } \\
\text { internação de Pernambuco }\end{array}$ & 2018 & $\begin{array}{l}\text { Educação, } \\
\text { Culturas e } \\
\text { Identidades }\end{array}$ & UFRPE \\
\hline SILVA & $\begin{array}{l}\text { A garantia do direito à educação para } \\
\text { adolescentes e jovens em cumprimento de } \\
\text { medida socioeducativa de internação }\end{array}$ & 2019 & Educação & UFPE \\
\hline
\end{tabular}

Fonte: Elaboração dos autores.

Silva (2019), em sua dissertação "O adolescente em conflito com a lei na escola", aborda o retorno dos adolescentes a escola regular, como o objetivo de investigar e analisar as experiências de adolescentes em conflito com a lei no ambiente escolar, objetivando identificar e discutir as principais dificuldades encontradas por esses adolescentes no retorno escolar, promovendo uma discussão em torno das nuances existentes nesta relação. A pesquisa foi realizada em um Centro de Atendimento Socioeducativo da cidade de São Bernardo do Campo, com adolescentes em medida de Liberdade Assistida. Para a coleta de dados foi utilizada o método de entrevista aberta com os indivíduos.

Os resultados da pesquisa apontaram para um ambiente no qual, na maioria das vezes, os adolescentes não se percebem pertencentes, por se deparar com atitudes que os diferenciam, indicando ainda a necessidade de repensar a maneira como os adolescentes são atendidos na rede regular de ensino e refletir acerca das questões para além do direito garantido. Foram constatados diferentes aspectos que coincidiram na relação existente entre medida socioeducativa, escola e adolescente em conflito com a lei, destacando-se as questões que perpassam pela (re)inserção, permanência e continuidade dos estudos, e o processo de aceitação e/ou aversão desses adolescentes no ambiente escolar. 
Na dissertação de Melo (2014) intitulado "A educação profissional na perspectiva do adolescente em conflito com a lei", faz uma análise acerca do ensino profissionalizante nas Unidades Socioeducativas, com o objetivo de apresentar a percepção de jovens em conflito com a lei acerca do curso Horticultor Orgânico executado pelo Instituto Federal do Amapá, através do Programa Nacional de Acesso ao Ensino Técnico e Emprego (PRONATEC), bem como investigar se foram atendidas às expectativas dos adolescentes participantes. Para a coleta de dados foram utilizadas anotações em diário de campo, entrevistas semiestruturadas e questionários individuais.

Com a pesquisa, a autora traz que os estudos demonstraram que apesar dos desafios e dificuldades encontrados no cotidiano do Centro Socioeducativo, tais como fuga, desinteresse, falta de motivação, e que, apesar desta população encontrar-se emocionalmente abalada devido à privação de liberdade e pelas transformações biológicas e emocionais provenientes desta etapa da vida, é possível realizar atividades voltadas para formação profissional.

Monteiro (2010), em sua dissertação, analisou a evasão e a defasagem escolar de adolescentes em conflito com a lei, com o objetivo de desvelar a memória de escola de adolescentes em conflito com a Lei e que cumprem medidas na Fundação da Criança e do Adolescente do Pará, na Unidade Socioeducativa de Internação de Val-de-Cães. A autora utilizou-se de entrevistas semiestruturadas e análises dos prontuários dos adolescentes.

Os resultados da pesquisa sobre a relação entre a situação socioeconômica dos adolescentes e a evasão escolar dos mesmos, sendo essa situação o fator que acabou por conduzi-los a um nível de exclusão social que os colocaram em contato com o mundo do crime. Foi evidenciado que a maioria dos adolescentes entrevistados abandonou a escola, sendo que o desinteresse é o fator que levou essa maioria a abandono. Segundo a autora, a escola demonstra-se despreparada, a família se sente incapaz e culpabilizada se afastando e resistindo, não conseguindo manter-se como espaço onde se constrói relações sociais. Os laços são rompidos e onde deveriam ser cuidados, são abandonados ou colocados em segundo plano em detrimento da busca pela sobrevivência.

Mariás (2014), em sua tese "A educação profissionalizante de jovens em conflito com a lei: interferências do despertar da puberdade na tarefa de inserção no mundo do trabalho", também discute a realidade da defasagem escolar dos adolescentes em conflito, bem como a dificuldade de encaminhamento aos cursos profissionalizantes, tornando ainda mais difícil cumprir o direito a garantia de acesso à educação e ao mercado de trabalho, previsto no Ecriad (1990). Este estudo tem como objetivo investigar a relação desses jovens com a escola e seus interesses profissionais, buscando conhecer os interesses dos adolescentes a fim de promover um espaço que propicie, e que chame atenção dos adolescentes, para os estudos. Para a coleta de dados utilizou-se conversas com os adolescentes em medida de semiliberdade.

A autora deparou-se com a dificuldade de reunir os adolescentes e o desinteresse dos mesmos em relação aos cursos profissionalizantes, bem como foi possível verificar, após o término da pesquisa, que o mundo contemporâneo contribui, decididamente, para que esses adolescentes não apostem em seu futuro profissional.

Piazzarollo (2015), em sua dissertação, buscou investigar os fatores de risco e de proteção na vida de adolescentes em conflito, também na perspectiva da evasão escolar. A autora realizou dois estudos, sendo que no primeiro foram aplicados questionários, em diversas instituições de atendimento socioeducacional à adolescentes em cumprimento de medida de Liberdade Assistida; no 
segundo estudo realizou-se entrevistas com adolescentes evadidos da escola e outros que frequentam o Ensino Médio.

Como resultados o trabalho destacou a importância dos relacionamentos interpessoais na escola e que o enfrentamento da evasão escolar inclua ações em vários níveis, contemplando o estudante, a família, a escola, os educadores e a organização social do país.

Silva (2018), em sua dissertação "Tempo da tranca, tempo da sala: a educação escolar de adolescentes em cumprimento de medida socioeducativa em um centro de internação de Pernambuco", buscou investigar o processo de educação escolar desenvolvido em Centro de Atendimento Socioeducativo (CASE), no qual adolescentes autores de atos infracionais cumprem medida socioeducativa de internação, refletindo sobre a importância dada à ação pedagógica desenvolvida no local, bem como, a necessidade de transformações nas práticas educativas para que favoreçam a melhor aprendizagem do aluno. Para a coleta de dados o autor realizou análise de documentos, observações e entrevistas com funcionários e alunos da instituição.

O autor concluiu que a instituição escolar existente nas unidades de socioeducação é vista como anexos de escolas regulares de ensino, ou seja, instituições norteadas por leis, propostas pedagógicas e políticas públicas que visam garantir o direito à educação. Porém são insuficientes para garantir o acesso e permanência do adolescente na escola, pois, segundo o autor, as ações educativas são suprimidas pela lógica carcerária da instituição, não sendo promovido um ensino direcionado ao público da instituição nem aos objetivos da medida socioeducativa, ou seja, sem levar em conta a realidade dos adolescentes.

Assim como o estudo anterior, Silva (2019) analisou, em sua tese, a política educacional destinada aos adolescentes e jovens em cumprimento de medida socioeducativa de internação e se ela estaria de acordo com o novo marco regulamentar do Sistema Nacional de Atendimento Socioeducativo (SINASE). Para isso, a autora, buscou conhecer a trajetória de vida e a experiência escolar de adolescentes em medida de internação, bem como as dificuldades encontradas pelos educadores durante as ações educativas com estes adolescentes, além das análises de documentos e da legislação que norteia o atendimento socioeducativo. Para a coleta de dados utilizou entrevistas e observações do meio.

Com a pesquisa, a autora apontou que, apesar de a instituição educacional estar de acordo com a legislação e a proposta do SINASE, a escola não consegue garantir o direito à educação dos adolescentes atendidos, considerando, que a esses estudantes tem sido negada a frequência escolar.

\subsection{Categoria IV - Educação não escolar e adolescentes em conflito com a lei}

Esta categoria reúne cinco produções, sendo elas todas as dissertações, as quais têm como enfoque a educação não escolar e adolescentes em conflito com a lei, ou seja, os aprendizados que ocorrem fora do ambiente escolar, mas que tem grande influência na formação do indivíduo. 
Quadro 4: Grupo 4 - Educação não escolar e adolescentes em conflito com a lei

\begin{tabular}{|c|c|c|c|c|}
\hline AUTOR & TÍTULO & ANO & PPG & IES \\
\hline CALEIRO & $\begin{array}{c}\text { Efeitos de um programa de intervenção analítico- } \\
\text { comportamental com adolescentes em conflito } \\
\text { com a lei }\end{array}$ & 2014 & $\begin{array}{c}\text { Análise do } \\
\text { Comportamento }\end{array}$ & UEL \\
\hline CERCAL & $\begin{array}{c}\text { Políticas públicas para adolescentes em conflito } \\
\text { com a lei: ação educativa e exercício da } \\
\text { cidadania? }\end{array}$ & 2007 & Educação & PUC-PR \\
\hline ROCHA & $\begin{array}{c}\text { Centro sócio-educativo ou escola para o crime? O } \\
\text { processo educativo em uma unidade de } \\
\text { internação de adolescentes em conflito com a lei }\end{array}$ & 2009 & Educação & UFAM \\
\hline WORM & $\begin{array}{c}\text { Adolescentes infratores: estudo acerca da medida } \\
\text { sócio-educativa de internação nas unidades do } \\
\text { centro de atendimento sócio-educativo ao } \\
\text { adolescente - casa como defesa da cidadania }\end{array}$ & 2007 & $\begin{array}{c}\text { Direito Político e } \\
\text { Econômico }\end{array}$ & UPM \\
\hline CÉSAR & $\begin{array}{c}\text { A FUNASE e a formação cidadã } \\
\text { Elestão Pública } \\
\text { para o } \\
\text { Desenvolvimento }\end{array}$ & UFPE \\
\hline
\end{tabular}

Fonte: Elaboração dos autores, (2020).

"Efeitos de um programa de intervenção analítico-comportamental com adolescentes em conflito com a lei", dissertação de Caleiro (2014), busca apresentar os resultados de um programa de intervenção analítico-comportamental em respostas de impulsividade aumentando o repertório de autocontrole em adolescentes em conflito com a lei. A pesquisa consiste em três estudos, sendo o primeiro um estudo teórico acerca do comportamento de autocontrole e na descrição dos fatores responsáveis pela prática infracional, o segundo estudo apresenta uma nova proposta de treino de autocontrole em adolescentes em conflito com a lei, que consiste na utilização de técnicas comportamentais trabalhadas com os adolescentes, e o terceiro estudo traz os resultados das ações realizadas no estudo dois com adolescentes em conflito em um Centro Socioeducativo.

Como resultados, a autora afirma que apenas a intervenção terapêutica não é suficiente para acabar com o problema de violência urbana, pois existem vários fatores que estão relacionados com o aumento de atos infracionais cometidos por adolescentes. Em relação à intervenção realizada, apresentou-se a redução de comportamentos de impulsividade avaliados a partir dos instrumentos aplicados antes e após a intervenção.

Cercal (2007), em sua dissertação "Políticas públicas para adolescentes em conflito com a lei : ação educativa e exercício da cidadania?", busca identificar a dinâmica da operacionalização das políticas públicas para adolescentes em conflito com a lei e se essa dinâmica se constitui em uma ação educativa de construção da cidadania, visando a melhora dos programas destinados a adolescentes das classes menos privilegiadas. Para a coleta de dados, a autora, realizou uma análise de documentos, da legislação e das políticas públicas relacionadas ao assunto, bem como a realização de entrevistas gravadas com funcionários e adolescentes da unidade socioeducativa.

A pesquisa evidenciou que a racionalidade neoliberal exerce influência no caráter e na operacionalização das políticas públicas e que a visão equivocada as transformam em políticas 
compensatórias, não sendo capaz de resolver os problemas gerados pela desigualdade e injustiças sociais e não cumprindo com seu objetivo que é proporcionar educação e cidadania aos adolescentes.

Rocha (2009) buscou, em sua dissertação "Centro socioeducativo ou escola para o crime? O processo educativo em uma unidade de internação de adolescentes em conflito com a lei", analisar o processo educativo desenvolvido em uma unidade de internação de adolescentes em conflito com a lei na perspectiva dos adolescentes, autores de atos infracionais graves, e dos seus educadores (professores, pedagogos, psicólogos e assistentes sociais) em uma unidade socioeducativa no Estado do Amazonas. Para a coleta de dados, o autor, utilizou-se das técnicas de observação, entrevistas individuais e grupos focais.

Como resultados, o estudo traz a identificação de uma forte influência de ações punitivas e segregacionistas, em que as normas constitucionais prevalecem sobre todos os demais, bem como, a desvalorização das ações educativas e culturais que são ofertadas na instituição, pelo fato de funcionarem sem condições adequadas. $O$ autor traz a necessidade de se refletir sobre o real papel das instituições socioeducativas, que devem se afastar de ações repressivas e punitivas, assim como a escola tem que assumir uma postura mais efetiva na aplicação das medidas socioeducativas.

"Adolescentes infratores: estudo acerca da medida socioeducativa de internação nas unidades do centro de atendimento socioeducativo ao adolescente - casa como defesa da cidadania", dissertação de Worm (2007), teve como objetivo representar uma fatia dessa população infanto-juvenil, o adolescente autor de ato infracional internado em Unidades do Centro de Atendimento Socioeducativo ao Adolescente (CASA) e a observância dos direitos e garantias fundamentais. A autora, inicialmente, faz um breve histórico acerca das políticas públicas para a infância e adolescência, bem como um estudo sobre a Doutrina de proteção integral, proposta pelo Ecriad (1990), para que fosse possível a análise da instituição, a fim de averiguar se o disposto em lei estava se fazendo cumprir na prática. Como instrumentos foram utilizadas observações e entrevistas, em diversas instituições da cidade de São Paulo.

A autora aponta que as ações educativas, bem como às instalações e o tratamento aos adolescentes não são satisfatórios e nem estão em concordância com a legislação, além do fato de que as medidas socioeducativas, em algum momento, não cumpriram seu objetivo, pois ao deixar a instituição o adolescente volta a cometer atos infracionais. A autora aponta, ainda, a necessidade de às políticas públicas acompanharem o desenvolvimento social e não retroceder às ações punitivas utilizadas anteriormente.

O último trabalho analisado foi "A FUNASE e a formação cidadã" dissertação de César (2014), no qual se objetivou analisar e verificar a contribuição efetiva da proposta educacional e a prática pedagógica desenvolvida pelos docentes que atuam na Funase/PE para a formação cidadã dos adolescentes e jovens infratores por ela acolhidos, refletindo sobre a educação um processo inclusivo voltado a crianças e jovens infratores na possibilidade de transformar vidas e oferecer perspectiva de futuro. Para a coleta de dados foram utilizadas análises de documentos e teóricos, bem como entrevistas com professores e educandos da instituição.

César (2014), em seus resultados, aponta que em razão das características de acessibilidade, adaptabilidade e aceitabilidade da instituição e dos fatores de superlotação, inadequação do espaço arquitetônico dificultam a formação dos educandos. A própria concepção de educação, especialmente, 
a qualidade do ensino, a proposta educacional e a prática pedagógica da Funase/PE não contribuem para a formação cidadã dos adolescentes e jovens em conflito com a lei nela acolhidos.

\section{DISCUSSÕES}

Com a pesquisa, seleção, organização e análise dos trabalhos, como mencionado anteriormente, foi possível verificar que as discussões acerca do trabalho com adolescentes em conflito com a lei é bem recente e ainda tem necessidade de mais atenção por parte dos pesquisadores. Nesse sentido, percebemos a necessidade de mais pesquisas, pois se tornou uma área que demanda urgência de reflexões e transformações, para que se possa aumentar a efetividade do trabalho socioeducativo no Brasil.

Após a análise e apresentação dos trabalhos selecionados, foi possível perceber que as pesquisas em que os autores tiveram contato direto com os adolescentes levaram em conta, também, as percepções deles acerca do assunto abordado. Porém, dado o número total de trabalhos selecionados, pode-se destacar que existem algumas lacunas sobre esse tema. Dentre elas destacamos que ainda são poucos trabalhos que levam em consideração o ponto de vista dos educandos, principalmente quando se trata de adolescentes em conflito com a lei.

Durante a análise das produções foi possível perceber a preocupação com a trajetória e às vivências dos adolescentes, bem como as influências dessas vivências em suas decisões e atitudes. A maioria dos trabalhos aborda as relações construídas entre o adolescente e os seus diversos grupos de convívio, como família, escola, amigos, e como essas relações podem influenciar o adolescente, favorecendo ou não a evasão escolar e o ato infracional.

No estudo de Gomes (2012), a autora trabalha com narrativas sobre a história de vida dos adolescentes, com o intuito de que eles se reconheçam como autores de suas próprias histórias, nesse estudo pode-se evidenciar a importância de se conhecer a história de vida desses sujeitos, para que se possa pensar em uma abordagem educacional significativa e mais efetiva.

Outro aspecto das produções que vale mencionar são os temas diferentes que são abordados em algumas delas, como o trabalho de Peripolli (2010) acerca das altas habilidades e superdotação de adolescentes em conflito e quais suas influências no processo de ensino e aprendizagem desses adolescentes, pois foi o único a abordar o tema em relação aos adolescentes em cumprimento de medida socioeducativa. O trabalho de Mariás (2014) sobre as interferências da puberdade no momento de inserção dos adolescentes no mercado de trabalho, também é uma temática diferente a ser pesquisada em relação aos adolescentes em conflito, pois tem relação direta com a perspectiva de futuro dos adolescentes, demonstrando que o mundo contemporâneo contribui, decididamente, para que esses adolescentes não apostem em seu futuro profissional.

A importância da educação no processo de cumprimento das medidas socioeducativas é bem perceptível na maioria dos trabalhos, os quais refletem sobre novas metodologias e formas de ensino, baseadas nas vivências dos educandos para uma formação mais significativa, como no estudo de Gomes (2016), que trabalha com as tecnologias de informação e comunicação para favorecer a aprendizagem dos adolescentes, Fernandes (2012), que faz seu estudo sobre as aulas de canto coral com adolescentes institucionalizados e, Costa (2012) e Bastos(2019), que trabalham as linguagens juntamente com a reflexão sobre o abandono escolar.

Apesar de serem produções que abordam temas bem interessantes e necessários para o melhor entendimento do trabalho com adolescentes em conflito com a lei, outra lacuna que apontamos, é a ausência de produções sobre o Ensino de Ciências e Educação Matemática, pois apenas um trabalho reflete sobre o ensino de matemática e seus significados para os adolescentes. 
De modo geral, os trabalhos analisados trazem a preocupação com a trajetória de vida, bem estar, e principalmente, com a formação dos adolescentes em conflito com a lei, sempre levando em conta a perspectiva do próprio adolescente sobre os temas abordados, nesse sentido, trazendo mais significado para o trabalho realizado. Porém se faz necessário dedicar atenção e ainda mais pesquisas neste contexto, abrangendo diversas outras áreas de conhecimento, para que este entendimento se torne uma ação efetiva no trabalho socioeducativo.

\section{CONCLUSÃO}

Este artigo teve como objetivo mapear e analisar estudos e produções acadêmicas de programas de pós-graduação no Brasil, que abordam temas sobre o processo de ensino e aprendizagem de adolescentes que cumprem medidas socioeducativas. Nesse sentido, realizamos o trabalho com o intuito de conhecer e explorar os trabalhos que estão sendo realizados para suprir as demandas desses sujeitos, em como novas maneiras de se trabalhar com os mesmos, de forma que o ensino seja mais significativo.

Após a seleção e análise das produções, foi possível constatar que a pesquisa acerca dos processos de ensino e aprendizagem de adolescentes em conflito com a lei ainda é escassa, e ainda há muitas lacunas a se preencher. Isso traz à tona a urgência de mais atenção a este contexto pouco explorado pelos pesquisadores.

Por ser um contexto que vem ganhando espaço há pouco tempo na pesquisa acadêmica, existe o fato de haver poucas pesquisas que abordam a perspectiva do próprio adolescente, levando em conta suas vivências, trajetórias, representações e entendimentos.Diversas pesquisas, elencadas anteriormente, demonstram a falta de interesse, dos adolescentes pela escola, resultando nos altos índices de evasão e defasagem escolar por parte desses sujeitos, bem como a ineficácia do sistema socioeducativo, que resulta na reincidência dos atos infracionais.

Em decorrência desta realidade, concluímos a necessidade de encontrar as falhas no sistema socioeducativo brasileiro, bem como a busca por novas metodologias e ações, em relação à Educação Matemática, que podem transformar esta realidade é urgente e necessita de mais estudos e pesquisas neste contexto.

\section{AGRADECIMENTO:}

A presente pesquisa foi realizada com o apoio da Fundação Araucária. 


\section{REFERÊNCIAS}

ALMEIDA, Thayane Carolina de. MASANO, Sonia Regina Vargas. Corpos marcados: uma análise histórica sobre a institucionalização de adolescentes em conflito com a lei. Mnemosine. Vol. 8, n.2, p. 161-183, 2012.

BARDIN, Laurence. Análise de conteúdo. São Paulo: Edições 70, 2011.

BASTOS, Sabrina Cecília Moraes. "Na escola, o cara tinha que ficá quieto, olhando pro quadro e escrevendo. Na rua, eu fazia o que eu queria": fenômenos representativos de adolescentes em conflito com a lei sobre as aulas de língua materna, escolarização e abandono escolar. 2019. 107 f. Dissertação (Mestrado em Linguística Aplicada) - Universidade do Vale do Rio dos Sinos, São Leopoldo, 2019.

BRASIL. Estatuto da Criança e do Adolescente. São Paulo: Cortez, 1990.

CALEIRO, Fernanda Mendes. Efeitos de um programa de intervenção analíticocomportamental com adolescentes em conflito com a lei. 2014. 135 f. Dissertação (Mestrado em Análise do Comportamento) - Universidade Estadual de Londrina, Londrina, 2014.

CERCAL, Silvana Sugamosto. Políticas públicas para adolescentes em conflito com a lei: ação educativa e exercício da cidadania? 2007. 99 f. Dissertação (Mestrado em Educação) Pontifícia Universidade Católica do Paraná, Curitiba, 2007.

CÉSAR, Isaura de Albuquerque. A funase e a formação cidadã. 2014. 126 f. Dissertação (Mestrado Profissional em Gestão Pública) - Universidade Federal de Pernambuco, Recife, 2014.

COSTA, Vinícius Oliveira. A relação entre a escola, o ensino de línguas e o abandono escolar: um olhar a partir das crenças e experiências de adolescentes com quem a lei entra em conflito. 2012. 119 f. Dissertação (Mestrado em Linguagem, identidade e subjetividade) - Universidade Estadual de Ponta Grossa, Ponta Grossa, 2012.

DOMINGUES, Isaneide. $\mathbf{O}$ coordenador pedagógico e a formação contínua do docente na escola. São Paulo: Cortez, 2014.

FERNANDES, José Fortunato. Educação musical de adolescentes em cumprimento de medida socioeducativa através do canto coral. 2012. 285 f. Tese (Doutorado em Música) Universidade Estadual de Campinas, Campinas, 2012.

GARCIA, Leandro Alves. Tessituras a/r/tográficas: ensino de artes visuais no centro de referência especializado de assistência social - São Gonçalo Do Amarante - RN. 2019. 131 f. Dissertação (Mestrado em Artes Visuais) - Universidade Federal da Paraíba, João Pessoa, 2019.

GOMES, Clara Costa. Adolescentes autores de atos infracionais e histórias de vida: construindo histórias em intervenção grupal no contexto da medida socioeducativa de liberdade assistida. 2012. 201 f. Dissertação (Mestrado em Psicologia Clínica e Cultura) Universidade de Brasília, Brasília, 2012.

GOMES, Marco Antônio Nogueira. Adolescentes em conflito com a lei: o ensinar e o aprender através das tecnologias da informação e da comunicação. 2016. $111 \mathrm{f}$. Tese (Doutorado em Informática na Educação) - Universidade Federal do Rio Grande do Sul, Porto Alegre, 2016. 
GOMES, Clara Costa. CONCEIÇÃO, Maria Inês Gandolfo. Sentidos da trajetória de vida para adolescentes em medida de liberdade assistida. Psicologia em Estudo, Maringá, v. 19, n. 1, p. 47-58, jan./mar. 2014.

MARIÁS, Kátia de Oliveira. A educação profissionalizante de jovens em conflito com a lei: interferências do despertar da puberdade na tarefa de inserção no mundo do trabalho. Belo Horizonte, 2014.

MACEDO, Valéria Gouveia de. Características psicossociais e de personalidade de adolescentes infratores em cumprimento de medida socioeducativa. 2016. $96 \mathrm{f}$. Dissertação (Mestrado em Psicologia) - Universidade Metodista de São Paulo, São Bernardo do Campo, 2016.

MASSARO, Camilla Marcondes. Entre o formal e o real: representações acerca do modelo disciplinar da fundação casa de Araraquara. 2008. 197 f. Dissertação (Mestrado em Educação) - Universidade Estadual Paulista "Júlio de Mesquita Filho", Araraquara, 2008.

MELO, Lucilene de Sousa. A educação profissional na perspectiva do adolescente em conflito com a lei. 2014. 101 f. Dissertação (Mestrado em Ciências) - Instituto de Agronomia Universidade Federal Rural do Rio de Janeiro, Seropédica - RJ, 2014.

MIRANDA, Geane Uliana. Adolescente em conflito com a lei e a lei em conflito com o adolescente: processo de criminalização da adolescência pobre. 2016. 189 f. Dissertação (Mestrado em Psicologia Institucional) - Universidade Federal do Espírito Santo, Vitória, 2016.

MONTEIRO, Regina Fernandes. Adolescentes em conflito com a lei: memórias e trajetórias de vivências na escola. 2010. 146 f. Dissertação (Mestrado em Educação) - Universidade Federal do Pará, Belém, 2010.

OLIVEIRA, Lucilene Lusia Adorno de. A delinquência e a (im)possibilidade de se significar como autor no discurso matemático. 2015. 193 f. Tese (Doutorado em Educação para a Ciência e a Matemática) - Universidade Estadual de Maringá, Maringá, 2015.

PADOVANI, Ricardo da Costa. Resolução de problemas sociais com adolescentes em conflito com a lei: estratégias de mensuração e intervenção. 2008. 242 f. Tese (Doutorado em Educação Especial) - Universidade Federal de São Carlos, São Carlos, 2008.

PACHECO, Janaína Thaís Barbosa. A construção do comportamento anti-social em adolescentes autores de atos infracionais: uma análise a partir das práticas educativas e dos estilos parentais. 2004. 120 f. Tese (Doutorado em Psicologia do Desenvolvimento) Universidade Federal do Rio Grande do Sul, Porto Alegre, 2004.

PARANÁ. Programa De Atendimento Socioeducativo Do Estado Do Paraná. Departamento de atendimento socioeducativo - DEASE. Secretaria de Estado da Justiça, Trabalho e Direitos Humanos. Curitiba, 2017.

PERIPOLLI, Arlei. Criatividade: caminho desenhante para altas habilidades/superdotação do adolescente em conflito com a lei. 2010. 192 f. Dissertação (Mestrado em Educação) Universidade Federal de Santa Maria, Santa Maria - RS, 2010.

PIAZZAROLLO, Dominique Costa Goes. Fatores de risco e de proteção presentes na vida de adolescentes cumprindo liberdade assistida: permanência e evasão escolar. 2015. 267 f. Dissertação (Mestrado em Psicologia) - Universidade Federal do Espírito Santo, Vitória , 2015. 
ROCHA, Wollace Scantbelruy da. Centro sócio-educativo ou escola para o crime? 0 processo educativo em uma unidade de internação de adolescentes em conflito com a lei. 2009. 171 f. Dissertação (Mestrado em Educação) - Universidade Federal do Amazonas, Manaus, 2009.

SANTOS, Elen Alves dos. As adolescentes em cumprimento de medida socioeducativa: um diálogo sobre as questões de gênero, escolarização, sociedade de consumo e ato infracional. 2016. 105 f. Dissertação (Mestrado em Educação) - Universidade de Brasília, Brasília, 2016.

SILVA, Lucélia Maria da. 0 adolescente em conflito com a lei na escola. 2019. 187 f. Dissertação (Mestrado em Educação) - Universidade Nove de Julho, São Paulo, 2019.

SILVA, Jamires Pereira da. Tempo da tranca, tempo da sala: a educação escolar de adolescentes em cumprimento de medida socioeducativa em um centro de internação de Pernambuco. 2018. 225 f. Dissertação (Mestrado em Educação, culturas e identidade) Universidade Federal Rural de Pernambuco, Recife, 2018.

SILVA, Karla Crístian da. A garantia do direito à educação para adolescentes e jovens em cumprimento de medida socioeducativa de internação. 2019. 207 f. Tese (Doutorado em Educação) - Universidade Federal de Pernambuco, Recife, 2019.

TAYLOR, Leticia Montes Penha. 1964 As representações do psicólogo na socioeducação: o saber ingênuo de adolescentes em internação provisória e em cumprimento de medidas socioeducativas no DEGASE / Letícia Montes Penha Taylor. - 2015.

TAKEUTI, Norma. Inconsistência simbólica e fragilidades identitárias. Psicologia em Revista, v. 8, n$^{\circ} .12,2002$, p. $32-44$.

VELOSO, Valdenir Batista. 0 jovem em conflito com a lei e o direito à educação básica. Reunião científica da ANPED. UFPR, Curitiba, 2016.

WORM, Naima. Adolescentes infratores: estudo acerca da medida sócio-educativa de internação nas unidades do centro de atendimento sócio-educativo ao adolescente casa como defesa da cidadania. 2007. 181 f. Dissertação (Mestrado em Direito Político e Econômico) - Universidade Presbiteriana Mackenzie, São Paulo, 2007.

Submissão: 14/10/2020

Aceito: 01/12/2020 